\title{
Evaluating the Effect of Arabic Engineering Students' Learning Styles in Blended Programming Courses
}

\author{
Ahmed Al-Azawei \\ University of Reading, Reading, UK, and \\ University of Babylon, Babel, Iraq
}

a.al-azawei@pgr.reading.ac.uk

\author{
Ali Al-Bermani \\ University of Babylon, \\ Babel, Iraq \\ ali@itnet.uobabylon.edu.iq
}

\author{
Karsten Lundqvist \\ University of Reading, \\ Reading, UK \\ k.o.lundqvist@reading.ac.uk
}

\begin{abstract} respective research remains rare.

Material published as part of this publication, either on-line or in print, is copyrighted by the Informing Science Institute. Permission to make digital or paper copy of part or all of these works for personal or classroom use is granted without fee provided that the copies are not made or distributed for profit or commercial advantage AND that copies 1) bear this notice in full and 2) give the full citation on the first page. It is permissible to abstract these works so long as credit is given. To copy in all other cases or to republish or to post on a server or to redistribute to lists requires specific permission and payment of a fee. Contact Publisher@InformingScience.org to request redistribution permission.
\end{abstract}

This study investigated the complex relationship among learning styles, gender, perceived satisfaction, and academic performance across four programming courses supported by an e-learning platform. A total of 219 undergraduate students from a public Iraqi university who recently experienced e-learning voluntarily took place in the study. The integrated courses adopted a blended learning mode and all learners were provided the same learning content and pathway irrespective of their individual styles. Data were gathered using the Index of Learning Styles (ILS), three closed-ended questions, and the academic record. Traditional statistics and partial least squares structural equation modelling (PLS-SEM) were performed to examine the proposed hypotheses. The findings of this research suggested that, overall, learning style dimensions are uncorrelated with either academic performance or perceived satisfaction, except for the processing dimension (active/reflective) that has a significant effect on the latter. Furthermore, gender is unassociated with any of the proposed model's constructs. Finally, there is no significant correlation between academic performance and perceived satisfaction. These results led to the conclusion that even though Arabic engineering students prefer active, sensing, visual, and sequential learning as do other engineering students from different backgrounds, they can adapt to a learning context even if their preferences are not met. The research contributes empirically to the existing debate regarding the potential implications of learning styles and for the Arabic context in particular, since

Keywords: learning styles, gender, academic performance, perceived satisfaction, blended learning.

\section{Introduction}

Promoting the learning process represents a key issue in educational practice. Factors that influence this process should be investigated in order to improve learning quality. Learning 
programming, for instance, is one of the most difficult modules in computer science (Gomes \& Carmo, 2006; Gomes \& Mendes, 2010; Lahtinen, Ala-Mutka, \& Järvinen, 2005). One possible reason behind such difficulty is the mismatch of teaching and learning styles. According to Felder (1996), there is bias in engineering instructions towards reflective, intuitive, verbal, and sequential styles and this, in turn, can negatively affect the learning experience of students who fall within the other axes. Additionally, this may lead to withdrawing from a course, leaner disinterest, and lower achievement (Felder \& Brent, 2005; Felder \& Silverman, 1988). The assumption of learning styles theory (LST) is that learners have different preferences in the way that they take in and process information and such preferences should be considered in the design of curricula. As a consequence, LST has been widely integrated into different learning modes in order to adapt learning environments in accordance with learner preferences (Akbulut \& Cardak, 2012; AlAzawei \& Badii, 2014). Furthermore, Lee and Sidhu (2015) recommended that multipleapproaches should be implemented to teach engineering students in order to respond to their individual learning styles. However, the theoretical base and potential implications of learning styles on educational practice have been questioned (Akbulut \& Cardak, 2012; Coffield, Moseley, Hall, \& Ecclestone, 2004; Mayer, 2011; Pashler, McDaniel, Rohrer, \& Bjork, 2009).

In this study, the learning preferences of engineering students in a public university in Iraq were firstly identified. Subsequently, the implications of LST on academic achievement and satisfaction in a blended learning setting were examined. Blended learning means "the thoughtful integration of classroom face-to-face learning experiences with online learning experiences" (Garrison \& Kanuka, 2004). Developing countries still face many issues that hinder a successful implementation of e-learning alongside traditional classroom teaching. The lack of financial resources can be accounted as one reason (Tarhini, Hassouna, \& Abbasi, 2015). On the other hand, Iraq, for example, is one of the richest developing countries in the Middle East, but it experienced a series of issues which affected its education system.

Higher education in Iraq has been considered the best of its kind in the Arab region (Kaghed \& Dezaye, 2009). However, due to the restrictions of the Baath regime on academic recruitment, the quality of teaching and learning has been negatively affected. The regime also influenced the appointment of leadership, controlled methods of teaching, curricula design, and the educational freedom of students. During the first and second Gulf war, approximately $84 \%$ of university buildings under different governorates were destroyed and their furniture and equipment looted (Mahmud, 2013). Moreover, e-learning technologies that have been applied years ago in developed countries to support traditional learning were only recently implemented in some of Iraqi universities. In the last five years, a few public educational institutions adopted the Learning Management System (LMS), Moodle (Modular Object-Oriented Dynamic Learning Environment), to give students an alternative opportunity to interact with their peers and instructors as well as facilitating information retrieval.

In this context, the teaching approach of 'one-size-fits-all' is predominant in the Iraqi higher education. All learners are provided the same learning content and pathway regardless of their individual preferences. Thus, the assumption of LST that meaningful learning can be achieved by matching teaching and learning styles has not been applied. Hence, it is feasible to conduct further examination into the impact of individual learning styles when such differences are not considered in the curricula design. This can extend the body of prior literature and highlight the possible effects of LST on the population under scrutiny.

\section{Research Objectives}

There is a scarcity of research to explore the relationship among learning styles, gender, and learning experience in higher education in the Middle East, more specifically in Iraq, because blended learning is a new trend in this nation. The present research pursues to fill in this gap. It 
was designed with the aim to identify the learning style distribution of Arabic engineering students across four programing courses. Subsequently, their preferences were compared to those of engineering students from other cultures. Finally, the potential impacts of learning styles as a deep level factor, and gender as a surface level factor on learning experience in a blended learning mode were investigated.

\section{Literature Review}

Although many studies have examined the relationship among learning styles, learner achievement, and perceived satisfaction, the contradictory findings have led to the present investigation. Furthermore, this analysis was performed with students who recently experienced blended learning and belong to an Arabic country, where there is a scarcity in such research. The importance of exploring LST in different educational contexts underlies the notion that learning styles are predetermined by students' culture (Wong, 2004). According to Cagiltay and Bichelmeyer (2000), from a surface perspective, it could be claimed that learning styles and culture are contradictory since the former seeks for individual differences, whereas the latter searches for what a group of people shared and what is common between them. However, the authors stated that there is an essential relationship between them because individuals "learn how to learn". Moreover, research indicates that within a particular culture, learners tend to have similar preferences for learning and perception when they are compared with others of a different one (Oxford \& Anderson, 1995). Hence, considering learning style groups and their implications on learning experience in different cultures can shade some light on the linkage between these two concepts. This section introduces the notion of learning styles, illustrates one of the most adopted learning style models, and discusses some of the related literature.

\section{Learning Styles}

Felder (1996) defined learning styles as "characteristic strengths and preferences in the ways they 'learners' take in and process information". Honey and Mumford (1992) stated that learning styles mean "a description of the attitudes and behaviours which determine an individual's preferred way of learning". Recently, LST has been dominant in adaptive educational hypermedia systems (AEHSs) (Akbulut \& Cardak, 2012; Al-Azawei \& Badii, 2014; Özyurt \& Özyurt, 2015). However, from a theoretical perspective, the issues that still surround learning styles include the absence of an acceptable definition, the overlap with other terminologies such as cognitive styles and learning approaches, the malleability of this trait, the wide number of learning style models, and the absence of valid instruments to measure such psychological trait (Al-Azawei \& Badii, 2014; Coffield et al., 2004; Graf, 2007; Pashler et al., 2009; Vanderheyden \& De Baets, 2015). From an empirical perspective, few studies have examined the effectiveness of learning styles (Akbulut \& Cardak, 2012). After a deep investigation that was conducted by Pashler et al. (2009), they concluded that "there is no adequate evidence base to justify incorporating learning styles assessments into general educational practice". Furthermore, Mayer (2011) reviewed eight studies that focused on the application of learning styles. This leads to the recommendation that "researchers and practitioners must search long and hard for the educational implications of styles research".

Educational psychologists have developed more than 71 learning style models (Coffield et al., 2004). These models were classified into five families: 'constitutionally-based learning styles and preferences', 'cognitive structure', 'stable personality type', 'flexibly stable learning preferences', and 'learning approaches and strategies'(Coffield et al., 2004). Here, the most dominant model in the previous studies is briefly described. 


\section{Felder and Silverman Learning Styles Model (FSLSM)}

This model was proposed by Felder and Silverman (1988) in order to diagnose learning styles of engineering students, but it has been successfully used to infer learning styles in other disciplines too (Cook \& Smith 2006; Hosford \& Siders 2010). The model is "neither original nor comprehensive" (Felder \& Silverman, 1988). However, it is dominant in educational research, specifically, in Technology Enhanced Learning (TEL) (Akbulut \& Cardak, 2012; Cha, Kim, Park, \& Yoon, 2006; Graf, 2007; Lee \& Sidhu, 2015). The four axes of this model are briefly described:

- Processing (active/reflective): learners process information either actively or reflectively. Active learners prefer to participate in learning tasks immediately and learn better in groups, whereas reflective learners adopt an analytical approach and prefer to study alone.

- Perception (sensing/intuitive): sensing learners prefer facts and follow tutors' approaches in problem-solving. Intuitive learners, on the other hand, prefer theories and tend to apply their innovation approaches in problem-solving.

- Input (visual/verbal): visual learners prioritise pictorial materials, for example, video, demonstration, and graphs, while verbal learners prefer written texts and listen to verbal explanation.

- Understanding (sequential/global): learners prefer to understand information either sequentially by following a step by step learning approach, or globally by getting the overall picture before reading surface-level details.

Felder and Silverman (1988) stated that engineering students tend to prefer active, sensing, visual, and sequential styles. Prior literature has confirmed this discussion as presented chronologically in Table 1.

Table 1: Engineering students learning style preferences

\begin{tabular}{|c|c|c|c|c|c|c|}
\hline Study & Country & Sample & Active & Sensing & Visual & Sequential \\
\hline $\begin{array}{l}\text { Van Zwanenberg et al. } \\
(2000)\end{array}$ & UK & 135 & $\mathrm{Y}^{*}$ & $\mathrm{Y}^{*}$ & $\mathrm{Y}^{*}$ & $\mathrm{Y}^{*}$ \\
\hline Kuri and Truzzi (2002) & Brazil & 351 & $60 \%$ & $74 \%$ & $79 \%$ & $50 \%$ \\
\hline Zywno (2003a) & Canada & 338 & $61 \%$ & $65 \%$ & $88 \%$ & $63 \%$ \\
\hline Litzinger et al. (2005) & United States & 235 & $\mathrm{Y}^{*}$ & $\mathrm{Y}^{*}$ & $\mathrm{Y}^{*}$ & $\mathrm{Y}^{*}$ \\
\hline Graf, Viola and Leo (2007) & $\begin{array}{l}\text { New Zealand } \\
\text { and Austria }\end{array}$ & 207 & $57 \%$ & $58 \%$ & $87 \%$ & $56 \%$ \\
\hline Gomes and Mendes (2010) & Portugal & 173 & $64.91 \%$ & $61.44 \%$ & $96.49 \%$ & $73.68 \%$ \\
\hline Fang and Zhao (2013) & China & 71 & $55 \%$ & $80 \%$ & $76 \%$ & $54 \%$ \\
\hline
\end{tabular}

*Authors stated that the dominant preferences were active, sensing, visual and sequential.

\section{Learning Styles and Learning Experience}

Thomas, Ratcliffe, Woodbury, and Jarman (2002) recruited 107 undergraduate students from an introductory programming course to explore the effect of learning styles on their performance. Reflective and verbal students scored significantly higher than active and visual groups. As such, they concluded that learning styles have positive implications on learner achievement. Similarly, Allert (2004) also found that from 117 undergraduate students, those who adopted reflective and verbal styles in an introductory computer science course did significantly better than active and visual learners. On the contrary, in the study conducted by Gomes and Mendes (2010), findings did not show any significant discrepancy between these two constructs (learning styles and academic performance). Moreover, a total of 270 undergraduate students took place in the study of Prajapati, Dunne, Bartlett, and Cubbidge (2011). Overall, results did not confirm any statistical significance between academic performance and the four dichotomies of FSLSM. 
In order to examine the effect of learning styles on perceived satisfaction and outcomes, Popescu (2010) adapted a web-based learning system according to learner styles. As a result, the study stated that learning styles play a significant role in the improvement of student satisfaction in the matched setting, rather than enhancing learning gain. On the other hand, Hong (2002) carried out a study to probe the influences of students and instructional variables that can affect their achievement and satisfaction. The subjects were 26 graduate students who enrolled in an online course. The study showed that learning styles, gender, and age were not related to satisfaction and performance, whereas computer skills positively affected their satisfaction. Further, learnerlearner interaction, course activities, asynchronous web-based conference and learning time as instructional variables were not related to satisfaction, whereas 'learner-instructor' interaction indicated a strong relation with satisfaction. Henry (2008) compared the relationship between learning styles and satisfaction of traditional and e-blended courses. The samples were 24 and 21 respectively. The significant outcome was only found in the input dimension where visual students in the e-blended course showed higher satisfaction in comparison to the verbal group.

In summary, the literature has produced inconsistent results. Accordingly, there is an indisputable need for further investigation in order to inform the current state of knowledge. In addition, research to cover this area in Arabic countries is scarce. The approach adopted in this study was, therefore, quantitative, to reveal the implications of this psychological trait and provide further evidence.

\section{Gender and Learning Experience}

Research on gender and academic performance in programming classes exhibited inconsistent findings (Lau \& Yuen, 2009). Pioro (2004) investigated the correlation between gender and performance in a computer programming course. A total of 25 undergraduate students took place in the study. The results demonstrated that women achieved significantly higher scores than men in the two measurements: multiple-choices questions and programming problem-solving. Considering the small sample size, such findings cannot be generalised. However, they were supported by measuring the association between gender and academic achievement of the 59 first-year undergraduate students in a fundamental programming language course (Al-Azawei \& Lundqvist 2014). Analyses suggested a significant correlation between these two factors; men achieved significantly higher performance than women. On the other hand, Mcdowell, Werner, Bullock, and Fernald (2003) did not detect a significant relationship between gender and performance of 555 undergraduate students who attended an introductory computer programming course. In the study that was carried out by Lau and Yuen (2009), 270 secondary school students were incorporated in the experiment. They established no statistical significance between gender and programming achievement.

Undoubtedly, the credibility of findings relies on a sample size. A larger sample can more accurately represent the total population (Cohen, Manion, \& Keith, 2007). As discussed above, studies that incorporated larger samples did not exhibit a significant correlation between gender and learning performance. However, cultural background should be taken into account because gender differences were considered as a key factor of culture (Gefen \& Straub, 1997).

\section{Research Methodology}

This research adopted a quantitative survey research design in order to understand the relationship between the identified variables. The survey research design was adequate because it aimed to identify the relationship among several factors (Gable, 1994). The criteria for sample selection entailed: (a) undergraduate students using a blended learning environment; and (b) the courses following a 'one-size-fits-all' teaching approach to reveal the extent to which learning experience 
is affected by learning styles even if they are mismatched. Hence, the purposive sampling approach was used (Cohen et al., 2007).

\section{The Model and Development of Hypotheses}

Many studies stated that learning style is one of the most important psychological factors that influence academic performance (Felder \& Brent, 2005; Kolb, 1984; Shaw, 2012; Lee \& Sidhu, 2015). Additionally, Dunn, Beaudry, and Klavas (2002) stated that learning styles are individual for everyone as a signature. Other literature, on the other hand, has criticised the theoretical base and empirical implications of this trait (Mayer, 2011; Pashler et al., 2009; Willingham, Hughes, \& Dobolyi, 2015). As such, this is a continuous area of research that should be investigated to provide conclusive evidence either to support or reject the integration of learning styles in educational work, especially in nations where such studies have been notably rare. In this context, in order to understand the relationship governing learning styles, academic performance, perceived satisfaction, and gender, a model was proposed based on the hypothesis that the four dimensions of FSLSM and gender are correlated with learning experience (Figure 1). Earlier literature identified more than 71 learning style models in which each model was based on particular dimensions and there is a dimensional overlap among the majority of them (Coffield et al., 2004).

In the present research, the FSLSM was adopted. Several criteria have led to its popularity. Firstly, this model was invented for educational purposes and engineering students in particular.

Moreover, it has a strong theoretical base due to its reliance on a deep investigation of the dominant teaching and learning styles in the engineering education (Felder \& Silverman, 1988). Additionally, literature has shown its suitability for educational studies that focus on TEL (Akbulut \& Cardak, 2012; Cha, Kim, Park, \& Yoon, 2006; Graf, 2007; Lee \& Sidhu, 2015). Fourthly, the proposed instrument to diagnose the model's dimensions has been validated (Litzinger, Lee, Wise, \& Felder, 2005; Zywno, 2003a). Another criterion of the FSLSM is the commercial aspects. Whilst some models charge a fee in order to identify learning styles, for instance, Dunn and Dunn model, Kolb's model, Myers and Briggs Type Indicator (MBTI), and Honey and Mumford's model (Brown, 2007), the questionnaire of this model is freely available. Finally, prior content-analysis reviews of learning styles-based educational hypermedia systems (EHSs) confirmed that this model has been widely used more than others (Akbulut \& Cardak, 2012; AlAzawei \& Badii, 2014; Özyurt \& Özyurt, 2015).

Other dimensions in the proposed framework are learner satisfaction and academic achievement. Perceived satisfaction in a blended learning environment is defined as "the sum of student's behavioural beliefs and attitudes that result from aggregating all the benefits that a student receives from using BELS [Blended E-Learning System]" (Wu, Tennyson, \& Hsia, 2010). Performance, on the other hand, represents the main objective of students in formal education because they cannot get the aimed degree without meeting an acceptable score. Moreover, Bolliger and Wasilik (2009) demonstrated that there is a link between learner satisfaction and performance. For the purposes of this research, six hypotheses were developed:

H1: There is a significant correlation between learning style dimensions and gender.

H2: Academic performance in blended programming courses is correlated with learning styles.

H3: Perceived satisfaction in blended programming courses is correlated with learning styles.

H4: There is a significant correlation between gender and academic performance in blended programming courses.

H5: There is a significant correlation between gender and perceived satisfaction in blended programming courses. 
H6: There is a significant correlation between academic performance and perceived satisfaction in blended programming courses.

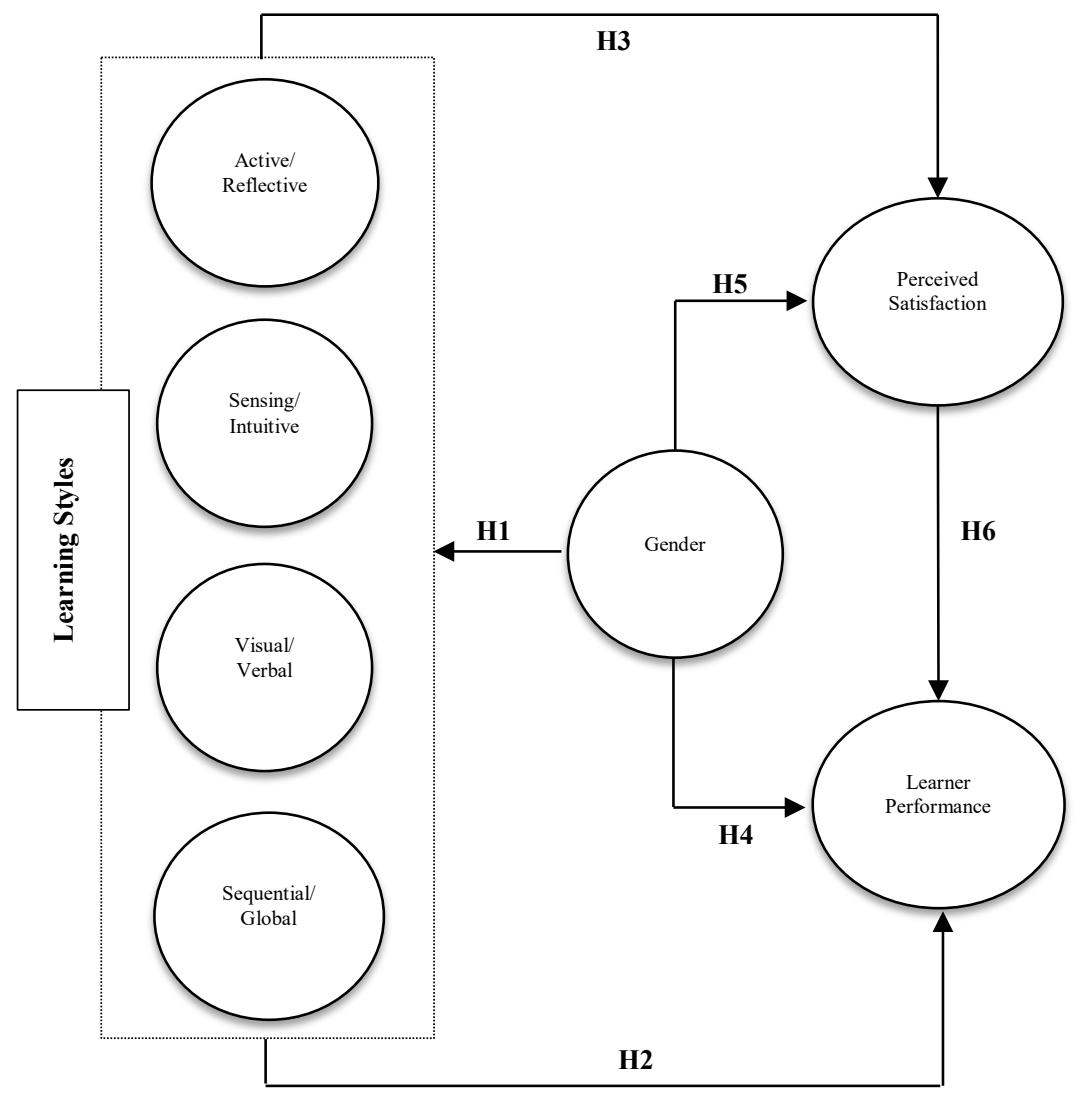

Figure 1: The research framework

\section{Participants and Contexts}

The research subjects comprised 219 undergraduate students enrolled in a College of Computer Science at a public university in Iraq: 65 freshmen, 90 sophomores, 41 juniors, and 23 seniors. The voluntary-based approach was used to recruit participants. At week eight of the second semester in the academic year 2014-2015, students were invited by their instructors to take part in the study and use the announcement page of Moodle. The majority of the students were between 18 to 22 years old. The subject team included 124 (56.6\%) females and 95 (43.4\%) males.

All modules were mandatory and taught over a 14-week course. Every week, students attended a two-hour lecture and a two-hour laboratory session. The theoretical concepts of each lecture were explained in the classroom, whereas problem-solving tasks were performed in laboratories. Further discussions pertaining to course content were also supported via Moodle. Communication tools such as wiki and forum were activated in all courses in order to improve the interaction between the students, as well as student and teacher. Additionally, all lectures were uploaded to the system as PowerPoint or PDF files. In order to avoid paper-based assessments, all theoretical exams were performed online via this LMS. In every course, lecturers referred the students to further reading materials on Moodle. Students had to get at least $50 \%$ to pass each course. The explored modules were:

(1) Fundamentals of Programming Language II (FPL II): a first-year module which covers the fundamentals of $\mathrm{C}++$ programming language. 
The Effect of Learning Styles in Blended Programming Courses

(2) Dynamic HTML (DHTML): a second-year module. The course represents an introduction to HTML, CSS, java script and HTML5.

(3) Network Security (NS): this course is taught in the third-year. In the laboratory tasks, simulation software is used to design and implement networks.

(4) PHP programming: a fourth-year course. It introduces designing dynamic websites using PHP and MySql database.

\section{Data Collection}

\section{The Index of Learning Styles (ILS)}

The ILS was proposed by Felder and Soloman (n.d.). It is a self-assessment tool to diagnose learning styles according to FSLSM. The instrument consists of 44 forced questions of which 11 are used to identify each dimension. Participants must rate themselves on each question by choosing the closest option to their preferences (either ' $a$ ' or ' $b$ '). The total scores for each style range from 0 to 11. Each dimension includes two dichotomies: a score of $0-1$ means a strong style for the left axis; 2-3, a moderate style for the left axis; 4-5, a mild style for the left axis; 6-7, a mild style for the right axis; 8-9, a moderate style for the right axis; and 10-11, a strong preference for the right axis. As discussed by Felder and Spurlin (2005), researchers can classify learner preferences into either three groups (e.g., active, balanced, and reflective) or two groups (e.g., active and reflective). In this study, however, the second approach was adopted as in related literature (Allert, 2004; Gomes \& Mendes, 2010; Henry, 2008; Popescu, 2010).

Pertaining to its validity and reliability, many studies supported both. Zywno (2003a) examined the psychometric properties of the ILS with 557 undergraduate engineering students as participants. The overall findings supported its reliability and validity. Furthermore, Felder and Spurlin (2005) surveyed several studies that focused on the instrument evaluation. This review led to the conclusion that the ILS is a valid measurement to diagnose learning styles of engineering students. Other research that confirmed the validity of the ILS encompassed, but not limited to, Cook and Smith (2006) and Litzinger et al. (2007).

The purpose of the research and how data will be manipulated were introduced in the beginning of the questionnaire. It was administered online to facilitate data collection. All items were identified as required to avoid receiving incomplete answers. The ILS was translated into the Arabic language because of the average English-language level of undergraduate students in Iraq. In order to ensure keeping the same meaning as in the original English version, the translation was performed in two stages. Questions that contained complicated meaning were firstly discussed with some colleagues in order to choose the most suitable Arabic words that fit the English ones. This step was followed by verifying the whole translation of the ILS by two PhD students in the United Kingdom who have high English proficiency and their mother language is Arabic.

As presented in Figure 2, there was an evident tendency of engineering students in Iraq towards active 150 (68.5\%), sensing $183(83.6 \%)$, visual $178(81.3 \%)$, and sequential $112(51.1 \%)$ styles. This result is consistent with other studies (Felder \& Spurlin, 2005; Gomes \& Mendes, 2010; Lee \& Sidhu, 2015; Litzinger, Lee, Wise, \& Felder, 2005; Van Zwanenberg, Wilkinson, \& Anderson, 2000). Two dimensions were roughly normally distributed about the zero scale, whereas perception (sensing/intuitive) and input (visual/verbal) were slightly skewed to the left. 

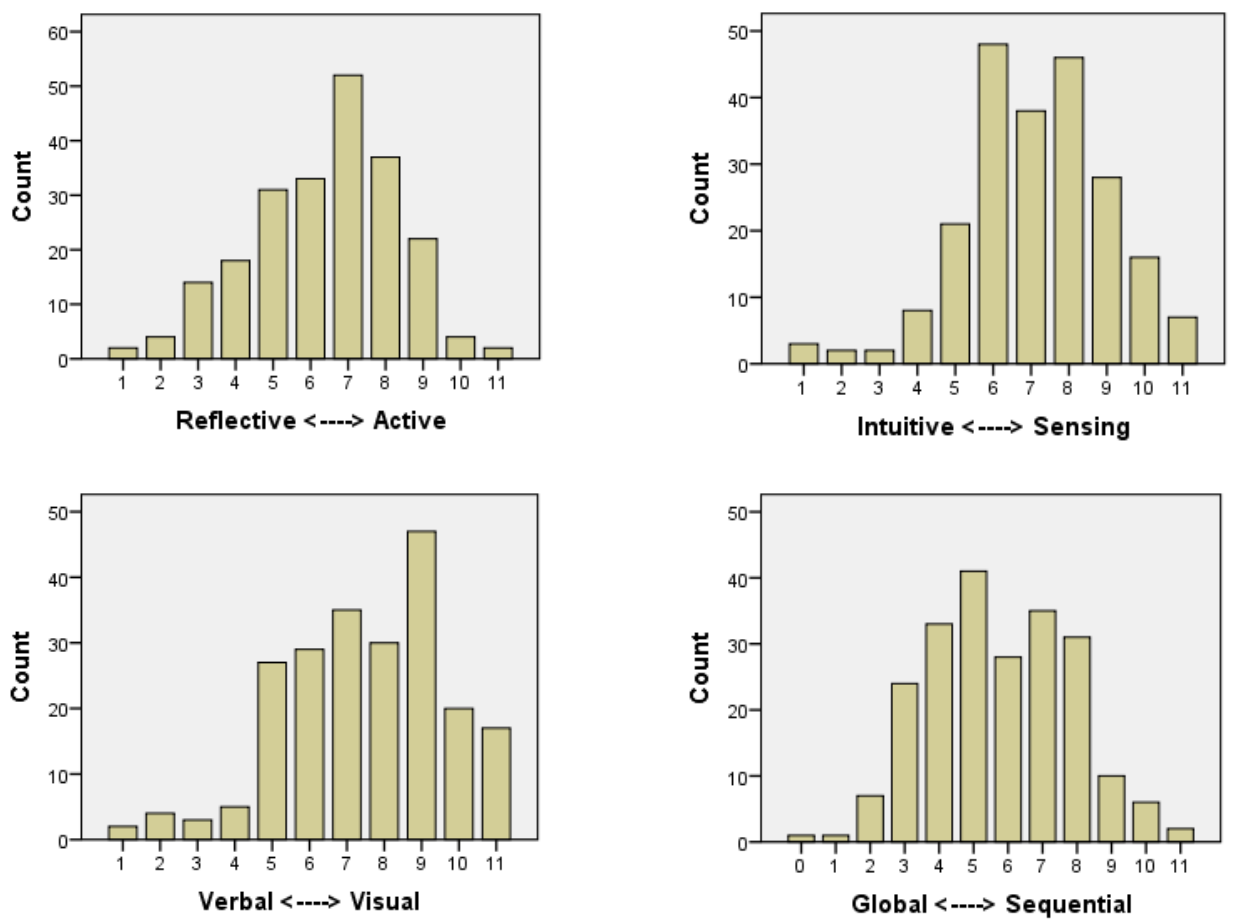

Figure 2: Scores of the four dimensions of learning styles

\section{Perceived satisfaction}

In order to identify learner satisfaction in the blended learning environment, three closed-ended questions with a 7-point Likert scale ranging from 1 'strongly disagree' to 7 'strongly agree' were used. The questions were adapted from Chiu, Hsu, Sun, Lin, and Sun (2005). Table 2 illustrates mean (M), standard deviation (SD), and Cronbach's alpha of learner satisfaction.

Table 2: Perceived satisfaction

\begin{tabular}{|l|c|c|}
\hline Item & M & SD \\
\hline 1) I am satisfied with the Blended E-Learning System (BELS) efficiency. & 4.91 & 1.63 \\
\hline 2) I am satisfied with the Blended E-Learning System (BELS) effectiveness. & 5.10 & 1.45 \\
\hline 3) Overall, I am satisfied with the Blended E-Learning System (BELS). & 5.33 & 1.33 \\
\hline Overall & 5.11 & 1.32 \\
\hline Cronbach $\alpha$ & \multicolumn{2}{|c|}{0.87}
\end{tabular}

\section{Academic record}

At the end of the modules, the overall mean score was used as an indicator of academic achievement. The maximum average for student performance was $50 \%$. This was calculated as follows:

- Two theoretical online exams in Moodle where a variety of questions was used, including multiple-choices, true-false, short answer and fill in the blank. The purpose of theoretical exams was to assess learner knowledge about the theoretical concepts of a module.

- Two laboratory tests that measured the students' problem-solving ability.

- Other learning activities such as their participation in online and classroom discussion, attendance, and assignments.

Table 3 depicts a summary of the main indicators to identify the four constructs of the research framework. 
Table 3: Indicators for each factor in the research framework

\begin{tabular}{|l|l|}
\hline Factor & Indicator \\
\hline Learning styles & 1) Processing: scores of active/reflective dimension \\
& 2) Perception: scores of sensing/intuitive dimension \\
3) Input: scores of visual/verbal dimension & 4) Understanding: scores of sequential/global dimension \\
\hline Gender & 1 for 'Male' and 2 for 'Female' \\
\hline Perceived satisfaction & $\begin{array}{l}\text { 1) I am satisfied with the Blended E-Learning System (BELS) efficiency. } \\
\text { 2) I am satisfied with the Blended E-Learning System (BELS) effectiveness. } \\
\text { 3) Overall, I am satisfied with the Blended E-Learning System (BELS). }\end{array}$ \\
\hline Academic achievement & Mean score of overall performance in a course \\
\hline
\end{tabular}

\section{Analysis Techniques}

The Statistical Package for Social Science (SPSS) software version 22 for Windows 7 and SmartPLSversion 3 were used to analyse the collected data. Both descriptive and inferential statistics were applied. These comprised mean, standard deviation, frequency, Pearson's correlation coefficient, one-way ANOVA, independent samples t-test, Cronbach's alpha, MANOVA, and partial least squares (PLS). Perceived satisfaction and learner performance were dealt as dependent variables, whereas learning styles and gender were identified as independent factors. Due to the homogeneity of subjects, other background information such as age group was not incorporated in the analysis. The hypotheses were measured at the significance alpha of 0.05 .

\section{Results}

A direct teaching approach was adopted in all courses. Therefore, styles and preferences of some students were undoubtedly mismatched. In such a learning environment, it is feasible to examine to what extent ignoring learner preferences can affect performance and satisfaction. Academic achievement was assessed by the total grades at the end of the modules, whereas student satisfaction was measured using three closed-ended questions. The MANOVA test was applied to investigate hypothesis H1. As shown in Table 4, there is no statistical significance between learning styles and gender. However, men have a more inclination toward active style than women.

Table 4: Gender and learning styles (MANOVA)

\begin{tabular}{|c|c|c|c|c|}
\hline \multicolumn{5}{|c|}{ Total Number of Participants $=219($ Male $=95$, Female $=124)$} \\
\hline Learning style & Gender & $\mathbf{M}$ & SD & MANOVA \\
\hline \multirow[t]{2}{*}{ Active } & Male & 6.65 & 1.97 & \multirow[t]{2}{*}{$\mathrm{F}=3.362, \mathrm{P}=0.068$} \\
\hline & Female & 6.17 & 1.90 & \\
\hline \multirow[t]{2}{*}{ Sensing } & Male & 6.96 & 1.89 & \multirow[t]{2}{*}{$\mathrm{F}=1.315, \mathrm{P}=0.253$} \\
\hline & Female & 7.26 & 1.93 & \\
\hline \multirow[t]{2}{*}{ Visual } & Male & 7.62 & 2.16 & \multirow[t]{2}{*}{$\mathrm{F}=0.506, \mathrm{P}=0.478$} \\
\hline & Female & 7.41 & 2.15 & \\
\hline \multirow[t]{2}{*}{ Sequential } & Male & 5.78 & 2.13 & \multirow[t]{2}{*}{$\mathrm{F}=0.059, \mathrm{P}=0.808$} \\
\hline & Female & 5.71 & 2.04 & \\
\hline
\end{tabular}

Figure 3 depicts the association between learning-style groups and academic achievement based on students completing the ILS ( $\mathrm{N}=219)$. However, the grades of two cases were missing, so the analysis was based on 217 observations. It is clear that student performance was approximately normally distributed according to learning styles dichotomies. In order to probe the potential association between learning style dimensions and learner performance (H2), one-way ANOVA was used. To begin with, we checked the correlation between these factors of each course alone, then the overall performance of all groups was analysed. 

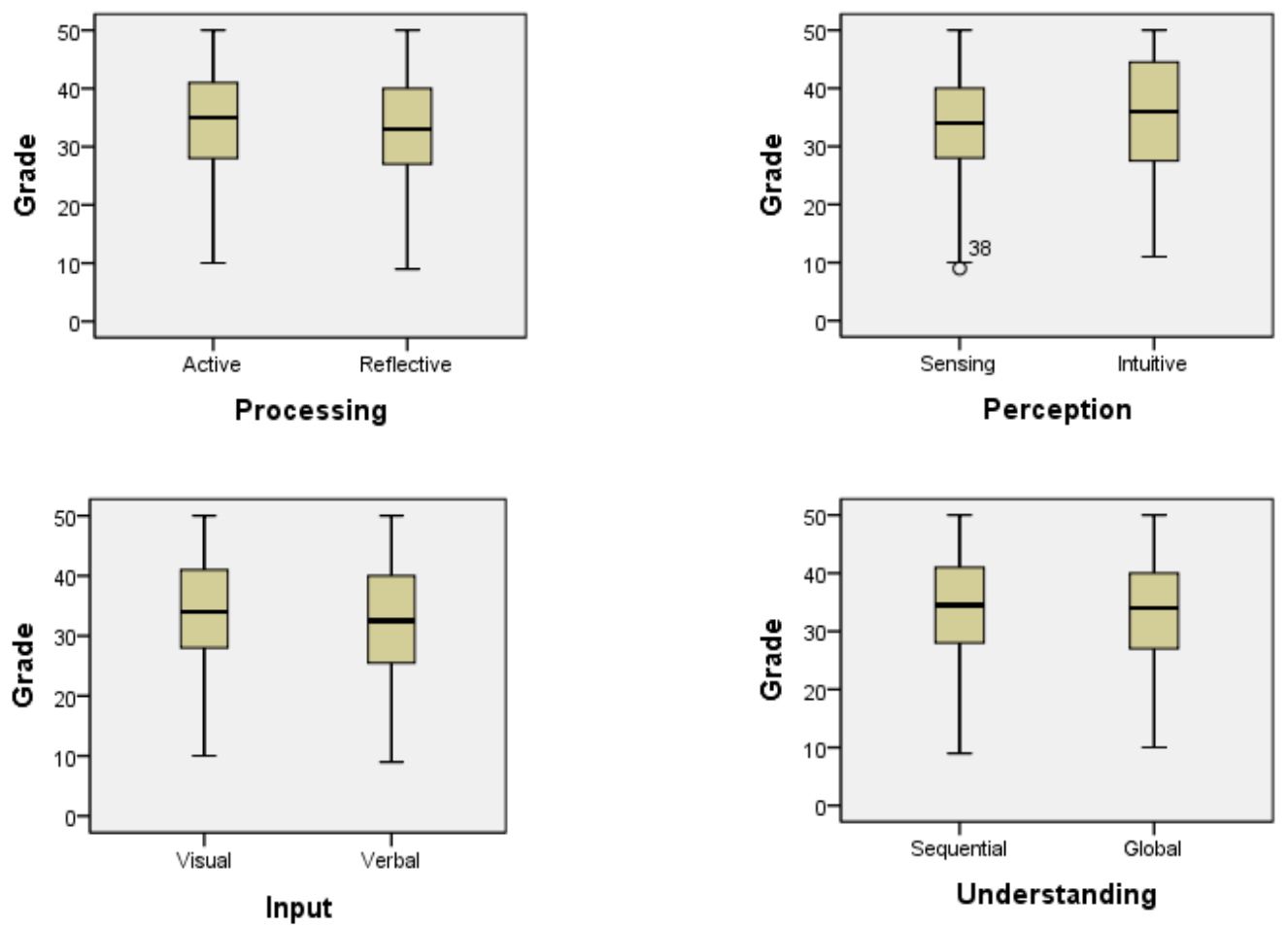

Figure 3: Boxplots of mean scores for each learning style dichotomy

As illustrated in Tables 5, 6 and 7, there were no significant variations in learner achievement of all courses. The only exception of these results was in the FPL II course where intuitive learners performed significantly higher grades than the sensing group $(\mathrm{P}=0.021)$.

Table 5: ANOVA results of learning styles and achievement (first and second years)

\begin{tabular}{|l|c|c|c|c|c|l|c|c|c|c|c|}
\hline \multicolumn{4}{|c|}{ First-year (Number of Participants=65) } & \multicolumn{4}{c|}{ Second-year (Number of Participants=89) } \\
\hline Dichotomy & $\mathbf{M}$ & SD & $\mathbf{d f}$ & $\mathbf{F}$ & $\mathbf{P}$ & Dichotomy & $\mathbf{M}$ & SD & df & F & P \\
\hline Active & 34.85 & 7.51 & 1,63 & 3.18 & 0.079 & Active & 30.55 & 8.74 & 1,87 & 0.10 & 0.74 \\
\hline Reflective & 31.28 & 6.37 & & & & Reflective & 29.84 & 11.66 & & & \\
\hline Sensing & 32.72 & 6.14 & 1,63 & 5.60 & 0.021 & Sensing & 29.92 & 9.68 & 1,87 & 0.62 & 0.43 \\
\hline Intuitive & 37.67 & 9.72 & & & & Intuitive & 32.06 & 10.45 & & & \\
\hline Visual & 34.71 & 7.01 & 1,63 & 3.62 & 0.062 & Visual & 30.32 & 9.45 & 1,87 & .001 & 0.97 \\
\hline Verbal & 30.46 & 7.93 & & & & Verbal & 30.24 & 11.45 & & & \\
\hline Sequential & 32.56 & 7.55 & 1,63 & 2.28 & 0.135 & Sequential & 32.18 & 8.63 & 1,87 & 3.42 & 0.063 \\
\hline Global & 35.29 & 6.94 & & & & Global & 28.39 & 10.62 & & & \\
\hline
\end{tabular}

Table 6: ANOVA results of learning styles and achievement (third and fourth years)

\begin{tabular}{|l|c|c|c|c|c|c|c|c|c|c|c|}
\hline \multicolumn{4}{|c|}{ Third-year (Number of Participants=40) } & \multicolumn{4}{c|}{ Fourth-year (Number of Participants=23) } \\
\hline Dichotomy & M & SD & df & F & P & Dichotomy & M & SD & df & F & P \\
\hline Active & 37.54 & 6.65 & 1,38 & 0.25 & 0.61 & Active & 38.20 & 8.44 & 1,21 & 0.39 & 0.53 \\
\hline Reflective & 38.63 & 6.59 & & & & Reflective & 41.33 & 2.88 & & & \\
\hline Sensing & 38.21 & 6.53 & 1,38 & 0.97 & 0.32 & Sensing & 39.35 & 6.961 & 1,21 & 1.34 & 0.25 \\
\hline Intuitive & 33.50 & 7.77 & & & & Intuitive & 33.67 & 14.01 & & & \\
\hline Visual & 37.84 & 6.42 & 1,38 & 0.05 & 0.81 & Visual & 38.52 & 8.34 & 1,21 & 0.026 & 0.87 \\
\hline Verbal & 38.44 & 7.43 & & & & Verbal & 39.50 & 2.121 & & & \\
\hline Sequential & 39.00 & 7.13 & 1,38 & 0.79 & 0.37 & Sequential & 37.71 & 8.194 & 1,21 & 0.43 & 0.51 \\
\hline Global & 37.14 & 6.10 & & & & Global & 40.00 & 7.874 & & & \\
\hline
\end{tabular}


Table 7: Summary of results of all groups (one-way ANOVA)

\begin{tabular}{|c|c|c|c|c|c|c|}
\hline \multicolumn{7}{|c|}{ Number of Participants=217 (Grades of two cases were missing) } \\
\hline \multirow[t]{2}{*}{ Dichotomy } & \multirow[t]{2}{*}{$\mathbf{N}$} & \multicolumn{2}{|c|}{ Course Result } & \multirow[t]{2}{*}{ df } & \multirow[t]{2}{*}{$\mathbf{F}$} & \multirow[t]{2}{*}{$\mathbf{P}$} \\
\hline & & $\mathbf{M}$ & SD & & & \\
\hline Active & 150 & 34.06 & 8.478 & \multirow[t]{2}{*}{1,215} & \multirow[t]{2}{*}{0.826} & \multirow[t]{2}{*}{0.36} \\
\hline Reflective & 67 & 32.87 & 9.918 & & & \\
\hline Sensing & 182 & 33.48 & 8.667 & \multirow[t]{2}{*}{1,215} & \multirow[t]{2}{*}{0.641} & \multirow[t]{2}{*}{0.42} \\
\hline Intuitive & 35 & 34.80 & 10.318 & & & \\
\hline Visual & 177 & 33.92 & 8.719 & \multirow[t]{2}{*}{1,215} & \multirow[t]{2}{*}{0.632} & \multirow[t]{2}{*}{0.427} \\
\hline Verbal & 40 & 32.68 & 9.919 & & & \\
\hline Sequential & 111 & 34.10 & 8.402 & \multirow[t]{2}{*}{1,215} & \multirow[t]{2}{*}{0.472} & \multirow[t]{2}{*}{0.493} \\
\hline Global & 106 & 33.26 & 9.493 & & & \\
\hline
\end{tabular}

Even though results did not show a significant correlation between learning styles and learner achievement, for further investigation, one way ANOVA was used to calculate the differences between the sixteen groups in FSLSM, as illustrated in Table 8.

Table 8: Mean and SD of the 16 groups

\begin{tabular}{|l|c|c|c|}
\hline Group & N & Mean & SD \\
\hline 1. Ac, Se, Vi, Seq & 66 & 34.12 & 7.236 \\
\hline 2. Ac, Se, Vi, Gl & 53 & 33.02 & 8.969 \\
\hline 4. Re, Se, Vi, Gl & 17 & 32.12 & 9.158 \\
\hline 5. Ac, Se, Ver, Seq & 8 & 30.88 & 8.823 \\
\hline 6. Ac, Se, Ver, Gl & 7 & 34.29 & 10.111 \\
\hline 7. Re, Se, Vi, Seq & 19 & 36.53 & 9.008 \\
\hline 8. Re, Se, Ver, Gl & 7 & 33.86 & 12.681 \\
\hline 9. Ac, In, Vi, Seq & 6 & 40.00 & 11.645 \\
\hline 10. Ac, Int, Vi, Gl & 8 & 38.13 & 10.869 \\
\hline 12. Re, In, Vi, Gl & 5 & 24.60 & 9.182 \\
\hline 15. Re, Int, Ver, Seq & 7 & 35.57 & 9.235 \\
\hline 16. Re, Int, Ver, Gl & 5 & 34.00 & 8.246 \\
\hline Total & 208 (Groups that included less than five cases were excluded) \\
\hline
\end{tabular}

Groups that included less than five cases were excluded. No significant variations were found between mean scores of all groups $(\mathrm{df}=15,200, \mathrm{~F}=1.340, \mathrm{P}=0.181)$. As such, we can safely conclude that learning styles and performance are independent factors.

Based on the Felder and Silverman Learning Style Dimensions (FSLSDs): \{(Active (Ac)/Reflexive (Re), (Sensing (Se)/Intuitive (In), (Visual (Vi)/Verbal (Ver), (Sequential (Seq)/Global (Gl)) $\}$, there are $16\left(2^{4}\right)$ possible Learning Style Groups (LSGs): \{(Ac, Se, Vi, Seq), (Ac, Se, Vi, Gl), (Re, Se, Ver, Seq), (Re, Se, Vi, Gl), (Ac, Se, Ver, Seq), (Ac, Se, Ver, Gl), (Re, Se, Vi, Seq), (Re, Se, Ver, Gl), (Ac, In, Vi, Seq), (Ac, In, Vi, Gl), (Re, In, Vi, Seq), (Re, In, Vi, Gl), (Ac, In, Ver, Seq), (Ac, In, Ver, Gl), (Re, In, Ver, Seq), (Re, In, Ver, Gl)\}. Figure 4 illustrates the distribution of the 16 learning style groups. 


\section{Distribution of Learning Style Groups}

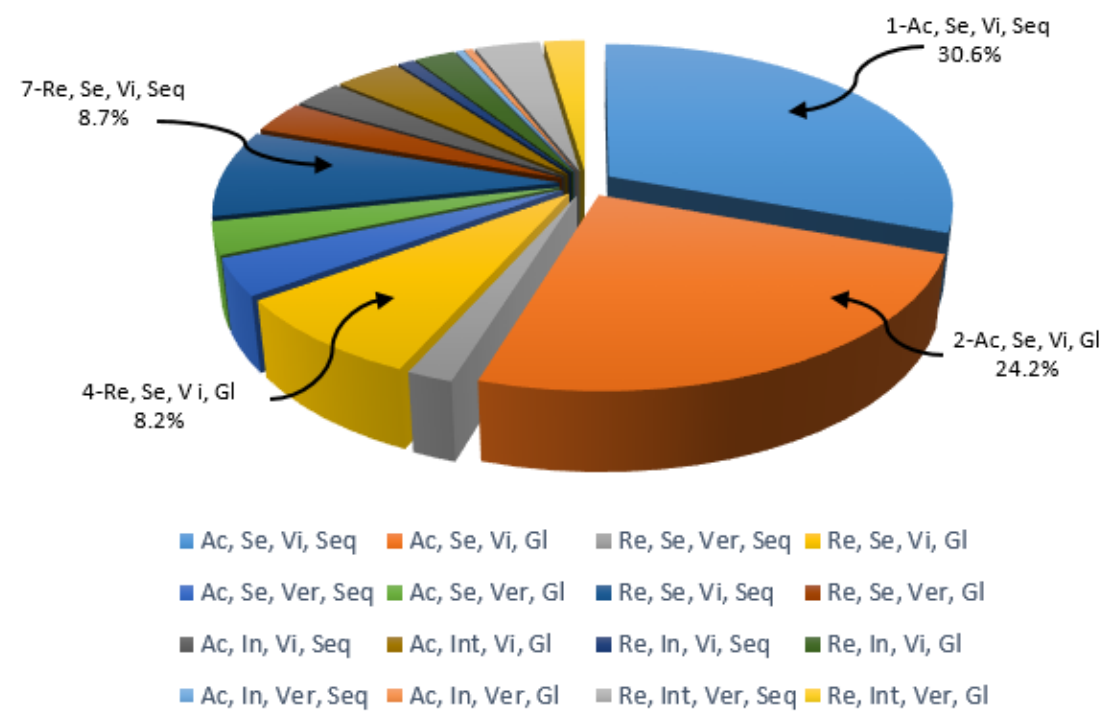

Figure 4: The distribution of learning style groups

Hypothesis H3 suggests that learning styles and perceived satisfaction are correlated. The Pearson correlation coefficient did not support this assumption except for the processing dimension. The results are $(\mathrm{r}=-0.179, \mathrm{P}=0.020),(\mathrm{r}=0.068, \mathrm{P}=0.382),(\mathrm{r}=-0.044, \mathrm{P}=0.569)$, and $(\mathrm{r}=-0.039, \mathrm{P}=0.616)$ for processing, perception, input, and understanding dimensions respectively. For further analysis, the t-test was conducted to reveal the difference in active/ reflective styles. We found that active learners were highly satisfied in the blended learning courses in comparison to another group $\left(\mathrm{M}_{\text {Sat_Active }}=5.273, \mathrm{SD}_{\text {Sat_Active }}=1.294, \mathrm{M}_{\text {Sat_Reflective }}=4.762, \mathrm{SD}_{\text {Sat_Reflective }}=1.325, \mathrm{~T}\right.$ (167) $=2.350, \mathrm{P}=0.020$ ).

Table 9 reports the findings of hypothesis H4, which assumes that there is a relationship between gender and academic performance. The result of the t-test did not confirm this hypothesis. Generally, females scored better than males $\left(\mathrm{M}_{\mathrm{Female}}=34.30, \mathrm{M}_{\mathrm{Male}}=32.88\right)$. However, the mean score differences between all groups were not statistically significant.

Table 9: Summary of results of gender and performance

\begin{tabular}{|c|c|c|c|c|c|c|c|}
\hline \multicolumn{8}{|c|}{ Number of Participants $=217$} \\
\hline & \multirow[t]{2}{*}{ Gender } & \multirow[t]{2}{*}{ Number } & \multicolumn{2}{|c|}{ Course Result } & \multirow[t]{2}{*}{ t-test } & \multirow[t]{2}{*}{$\mathbf{F}$} & \multirow[t]{2}{*}{$\mathbf{P}$} \\
\hline & & & $\mathbf{M}$ & SD & & & \\
\hline \multirow[t]{2}{*}{ Year 1} & Male & 30 & 35.50 & 7.651 & \multirow[t]{2}{*}{$\mathrm{T}(63)=1.689$} & \multirow[t]{2}{*}{0.809} & \multirow[t]{2}{*}{0.096} \\
\hline & Female & 35 & 32.46 & 6.874 & & & \\
\hline \multirow[t]{2}{*}{ Year 2} & Male & 43 & 28.84 & 11.191 & \multirow[t]{2}{*}{$\mathrm{T}(87)=1.371$} & \multirow[t]{2}{*}{7.728} & \multirow[t]{2}{*}{0.174} \\
\hline & Female & 46 & 31.67 & 8.181 & & & \\
\hline \multirow[t]{2}{*}{ Year 3} & Male & 11 & 39.09 & 7.968 & \multirow[t]{2}{*}{$\mathrm{T}(38)=0.657$} & \multirow[t]{2}{*}{1.697} & \multirow[t]{2}{*}{0.515} \\
\hline & Female & 29 & 37.55 & 6.063 & & & \\
\hline \multirow[t]{2}{*}{ Year 4} & Male & 8 & 36.13 & 11.103 & \multirow[t]{2}{*}{$\mathrm{T}(21)=1.096$} & \multirow[t]{2}{*}{6.493} & \multirow[t]{2}{*}{0.285} \\
\hline & Female & 15 & 39.93 & 5.725 & & & \\
\hline \multirow[t]{2}{*}{ Overall } & Male & 93 & 32.88 & 10.360 & \multirow[t]{2}{*}{$T(215)=1.156$} & \multirow[t]{2}{*}{13.13} & \multirow[t]{2}{*}{0.24} \\
\hline & Female & 124 & 34.30 & 7.696 & & & \\
\hline
\end{tabular}

To measure the association between gender and satisfaction (H5), the t-test was carried out. The results indicated that both males and females were satisfied in the blended learning courses re- 
gardless of their gender differences $\left(\mathrm{M}_{\text {Male }}=5.09, \mathrm{SD}_{\text {Male }}=1.332, \mathrm{M}_{\text {Female }}=5.127, \mathrm{SD}_{\text {Female }}=1.326, \mathrm{~T}\right.$ $(167)=0.135, \mathrm{~F}=0.253, \mathrm{P}=0.89)$.

Based on some literature, for example, Bolliger and Wasilik (2009) and Shin and Kang (2015), we expected to find a significant correlation between academic performance and perceived satisfaction. However, the Pearson correlation coefficient exhibited that these two factors are uncorrelated $\left(\mathrm{M}_{\text {Performance }}=33.69, \mathrm{SD}_{\text {Performance }}=8.941, \mathrm{M}_{\text {Satisfaction }}=5.11, \mathrm{SD}_{\text {Satisfaction }}=1.321, \mathrm{r}=-0.092\right.$, $\mathrm{P}=0.240$ ). For further analysis, one-way ANOVA was used to explore the difference in learning styles of students in accordance with their year of study. Table 10 shows that there is no statistical significance among learning style scores of all groups.

Table 10. Comparison of the ILS scores among the four groups

\begin{tabular}{|c|c|c|c|c|c|c|c|c|c|}
\hline \multicolumn{2}{|c|}{$\begin{array}{l}\text { Number of Partici- } \\
\text { pants }=219\end{array}$} & \multicolumn{2}{|c|}{ Processing } & \multicolumn{2}{|c|}{ Perception } & \multicolumn{2}{|c|}{ Input } & \multicolumn{2}{|c|}{ Understanding } \\
\hline Study Year & $\mathbf{N}$ & $M$ & $S D$ & $M$ & $S D$ & $M$ & $S D$ & $M$ & $S D$ \\
\hline Year One & 65 & 6.55 & 1.969 & 6.97 & 2.054 & 7.38 & 2.052 & 5.54 & 2.107 \\
\hline Year Two & 90 & 6.22 & 2.043 & 6.92 & 2.084 & 7.40 & 2.435 & 5.88 & 2.145 \\
\hline Year Three & 41 & 6.07 & 1.822 & 7.51 & 1.287 & 7.56 & 1.747 & 5.46 & 1.859 \\
\hline Year Four & 23 & 7.04 & 1.551 & 7.70 & 1.690 & 8.13 & 1.984 & 6.26 & 2.094 \\
\hline Total & 219 & 6.38 & 1.944 & 7.13 & 1.921 & 7.50 & 2.160 & 5.74 & 2.079 \\
\hline \multicolumn{2}{|l|}{ ANOVA test } & \multicolumn{2}{|c|}{$\begin{array}{l}F=1.619, d f=3 \\
215, p=0.186\end{array}$} & \multicolumn{2}{|c|}{$\begin{array}{l}F=1.726, d f=3, \\
215, p=0.163\end{array}$} & \multicolumn{2}{|c|}{$\begin{array}{l}F=0.788, d f=3, \\
215, p=0.502\end{array}$} & \multicolumn{2}{|c|}{$\begin{array}{l}F=1.059, d f=3 \\
215, p=0.367\end{array}$} \\
\hline
\end{tabular}

\section{Analysis of Structural Equation Modelling}

In this step, the model was examined using the PLS method. As discussed by Lowry and Gaskin (2014), the first generation of statistical techniques such as correlations, the difference between groups (e.g., ANOVA and t-tests), and regressions, have limited abilities, specifically, to understand the causal relationship in a model, whereas PLS-SEM is a very strong technique in such cases. Accordingly, PLS modelling was also used to confirm the results of the traditional tests. This technique has the ability to estimate the association path in a model and, thus, it has been widely used to develop a theory and predict a construct (Chin, 1998; Hair, Black, Babin, Anderson, \& Tatham, 2006). Another advantage of PLS is that it can deal with a small sample size (Barrio-garcía, Arquero, \& Romero-frías, 2015; Cheng \& Chau, 2014). Lowry and Gaskin (2014) recommended two ways to identify a sufficient sample size for PLS. In the former, multiplying 10 times of "the largest number of structural paths directed at a particular construct in the structural model" is suggested. In the latter, the statistical power of the multiple regression tests is recommended to be considered. Based on the first method, 60 cases represent an acceptable sample size, whereas 97 observations are required to achieve $80 \%$ of a statistical power and a significant alpha of 5\%. Thus, our sample size (219) met both recommendations. The results of the path associated in the model are illustrated in Table 11 and Figure 5.

Table 11: Results of the structural equation model

\begin{tabular}{|l|c|c|c|c|c|c|}
\hline Hypotheses & \multicolumn{5}{|c|}{ Standardised estimate } \\
\hline & $\begin{array}{c}\text { Direct } \\
\text { effect }\end{array}$ & t-value & $\begin{array}{c}\text { Indirect } \\
\text { effect }\end{array}$ & t-value & $\begin{array}{c}\text { Total } \\
\text { effect }\end{array}$ & Finding \\
\hline Dependent: Learning styles & & & & & & \\
\hline H1: Gender $\rightarrow$ Learning styles & & & & & & \\
\hline Gender $\rightarrow$ Processing & -0.121 & 1.817 & & & -0.121 & Rejected \\
\hline Gender $\rightarrow$ Perception & 0.082 & 1.201 & & & 0.082 & Rejected \\
\hline Gender $\rightarrow$ Input & -0.042 & 0.610 & & & -0.042 & Rejected \\
\hline Gender $\rightarrow$ Understanding & -0.007 & 0.096 & & & -0.007 & Rejected \\
\hline
\end{tabular}




\begin{tabular}{|c|c|c|c|c|c|c|}
\hline \multirow[t]{2}{*}{ Hypotheses } & \multicolumn{6}{|c|}{ Standardised estimate } \\
\hline & $\begin{array}{c}\text { Direct } \\
\text { effect }\end{array}$ & t-value & $\begin{array}{c}\text { Indirect } \\
\text { effect }\end{array}$ & t-value & $\begin{array}{l}\text { Total } \\
\text { effect }\end{array}$ & Finding \\
\hline \multicolumn{7}{|l|}{ Dependent: Performance } \\
\hline \multicolumn{7}{|l|}{ H2: Learning styles $\rightarrow$ Performance } \\
\hline Processing $\rightarrow$ Performance & 0.043 & 0.560 & -0.018 & 0.881 & 0.026 & Rejected \\
\hline Perception $\rightarrow$ Performance & -0.066 & 0.762 & & & -0.066 & Rejected \\
\hline Input $\rightarrow$ Performance & 0.047 & 0.542 & 0.004 & 0.430 & 0.051 & Rejected \\
\hline Understanding $\rightarrow$ Performance & 0.018 & 0.242 & -0.010 & 0.746 & 0.008 & Rejected \\
\hline H4: Gender $\rightarrow$ Performance & 0.083 & 1.153 & -0.014 & 0.687 & 0.069 & Rejected \\
\hline H6: Satisfaction $\rightarrow$ Performance & -0.087 & 1.105 & & & -0.087 & Rejected \\
\hline \multicolumn{7}{|l|}{ Dependent: Satisfaction } \\
\hline \multicolumn{7}{|l|}{ H3: Learning styles $\rightarrow$ Satisfaction } \\
\hline Processing $\rightarrow$ Satisfaction & 0.202 & $2.623^{* *}$ & & & 0.202 & Supported \\
\hline Perception $\rightarrow$ Satisfaction & -0.094 & 1.085 & & & -0.094 & Rejected \\
\hline Input $\rightarrow$ Satisfaction & -0.043 & 0.638 & & & -0.043 & Rejected \\
\hline Understanding $\rightarrow$ Satisfaction & 0.110 & 1.408 & & & 0.110 & Rejected \\
\hline H5: Gender $\rightarrow$ Satisfaction & 0.049 & 0.681 & -0.031 & 1.314 & 0.018 & Rejected \\
\hline
\end{tabular}

${ }^{* *} \mathrm{P}<0.01$

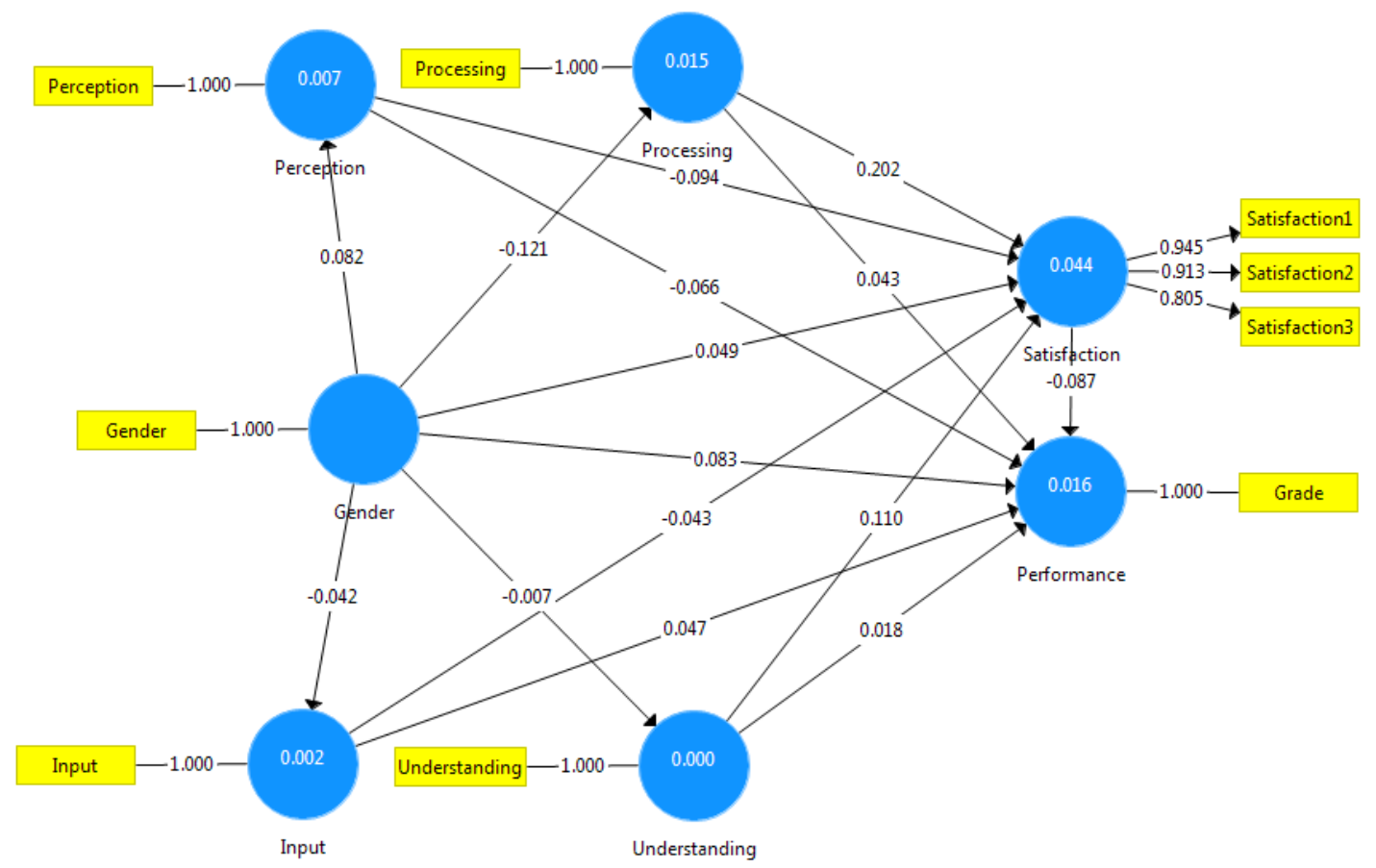

Figure 5: The PLS model

\section{Discussion}

In this study, six hypotheses were developed to examine the relationship among learning styles, gender, learner satisfaction, and academic achievement. Overall, traditional statistical analysis and PLS approach did not confirm the LST in the present research. However, one noteworthy finding is that the satisfaction of active learners was significantly higher than students who had a reflective preference in blended programming courses.

A key objective of this research was to identify learning styles of Arabic engineering students and compare them with engineering students from other cultures. Undoubtedly, there are many differ- 
ences between Arabic students and those from Western countries in the educational system, social life, ethnicity, and cultural background. Based on such diversity, it was anticipated that Arabic engineering students will have different learning styles than those from other backgrounds since this trait is linked to both nature and nurture (Hsu, 1999). Furthermore, the literature states that learning styles of students who belong to a particular culture are different from those who came from another one (Oxford \& Anderson, 1995). However, the ILS indicated that the main preferences of the study's subjects were active, sensing, visual, and sequential. This means that engineering students in Iraq have similar learning styles and preferences as engineering students from different countries, as presented in Table 1 and discussed in previous research (Felder \& Spurlin, 2005; Gomes \& Mendes, 2010; Lee \& Sidhu, 2015; Litzinger, Lee, Wise, \& Felder, 2005; Van Zwanenberg, Wilkinson, \& Anderson, 2000). Moreover, Table 8 shows that from the 16 combinations, groups 1 (Ac, Se, Vi, Seq), 2 (Ac, Se, Vi, Gl), and 7 (Re, Se, Ver, Gl) accounted for $63.9 \%$ of the overall preferences of students. This result confirmed the findings of the study that was conducted in Canada by Zywno (2003b) about the dominant learning style groups of engineering students. Moreover, Table 10 depicts that engineering students have similar styles regardless of their stage of study. It is clear that there was no significant difference of learning style distribution among the four groups. On one hand, the overall results can support the validity of the ILS to identify learning styles of engineering students irrespective of their cultural background. On the other, if the impacts of LST can be proven, educators in engineering institutions should consider the preferences of all students rather than emphasising their teaching approaches on reflective, intuitive, verbal, and sequential styles as discussed by Felder (1996).

The analysis of hypothesis $\mathrm{H} 1$ did not demonstrate a significant correlation between all learning style dimensions and gender to support the analysis of Demirbas and Demirkan (2007). However, males were more likely to prefer active style in comparison to females. This result partially supported the study of Prajapati et al. (2011) where they found that more females than males adopted visual and reflective styles. Generally, in most Arabic countries there are some cultural and religious factors that may affect the interaction of females in a public environment. This may explain why men are more active than women in such contexts. Examining online interaction behaviour in accordance with gender differences can shed more light on the relationship between gender, culture, and communication patterns. However, this investigation is out of the scope of this research.

This study also aimed to explore the correlation between learning styles and student achievement in the blended learning system (H2). Learning style dimensions did not appear to influence or predict learner achievement. Mean scores of students were very similar regardless of their styles. One explanation is that preferences of all learners were addressed in the blended learning courses. However, noticing that students were taught in a direct teaching approach and same learning materials and pathway were provided for all of them, a second explanation may be plausible. It suggests that students can adapt to teaching styles and learning contexts to meet their learning aims irrespective of their individual preferences. This notion was also supported by the ANOVA test as shown in Table 8 . The results clearly indicate that there is no significant variation between mean scores in all groups. A possible indication from this discussion is that learning styles are a malleable trait that can be adapted as learners experience different learning environments. The finding of this hypothesis is consistent with prior literature (Gomes \& Mendes, 2010; Prajapati et al., 2011). However, other research suggested a strong correlation between some dimensions of FSLSM and learner performance (Allert, 2004; Thomas et al., 2002). Such contradictory findings may be accounted by other learning circumstances rather than LST.

Another objective of this research was to investigate the correlation between learning styles and learner satisfaction $(\mathrm{H} 3)$. The processing dimension is the only one that showed a strong correlation with perceived satisfaction. The PLS method also exhibited that processing dimension was a 
predictive factor of perceived satisfaction (Table 11). Active learners were more satisfied in the blended courses. According to Felder and Silverman (1988), one of the strongest preferences of active students is working with other peers. The use of LMS alongside the traditional classrooms might improve the interaction between 'student-instructor' and 'student-student' because all available communication tools such as chat, forum and wiki were activated in the system. This result is to some extent inconsistent with studies that pointed out the positive effect of learning styles on learner satisfaction (Brown, 2007; Popescu, 2010). However, they accommodated elearning systems according to individual styles, whereas this study examined the possible consequences of learning styles in a classical learning environment where all students were provided with the same learning content. On the other hand, our result was in accordance with Hong (2002) and partially supported the findings of Henry (2008). Despite the fact that Shaw (2012) used Kolb's Learning Styles Inventory (LSI) to infer on learning styles, the findings exhibited that these two constructs were uncorrelated, so it supported our analysis.

With regard to the influence of gender, it did not seem to affect either academic performance (H4) or learning satisfaction (H5) in a blended learning mode. As discussed previously, related literature introduced inconclusive results. However, many of the reviewed studies agreed that gender is uncorrelated with academic achievement (Hong, 2002; Mcdowell et al., 2003; Lau \& Yuen, 2009; Vanderheyden \& De Baets, 2015; Yukselturk \& Bulut, 2009). Following gender and perceived satisfaction analysis, Askar, Altun, and Ilgaz (2008), Adas and Shmais (2011), Hong (2002), and Vanderheyden and De Baets (2015) reported that gender is an unaffected factor on perceived satisfaction as found in the present research. Naaj, Nachouki, and Ankit (2012), on the other hand, indicated that gender differences of students who experienced blended learning were significantly linked to their satisfaction.

Theoretically, it could be a synergy between learner performance and perceived satisfaction. High satisfaction with an educational system, teacher characteristics, or learning environment may encourage students to achieve better than unsatisfied peers. Hence, Bolliger and Wasilik (2009) concluded that there is a link between perceived satisfaction and learning outcomes. Our analysis, on the other hand, did not reveal such significant correlation (H6). This may be because all courses were compulsory and, thus, students have done their best to finish them successfully. Investigating this correlation in a voluntary course may reveal different results. Such outcome contrasted with the study of Shin and Kang (2015), who found a strong correlation between learner performance and satisfaction. However, they used student perceptions as an indicator of performance instead of relying on real academic achievement. This represents a clear limitation in such findings, whereas our study used real scores of participants.

Based on this quantitative investigation, we conclude the following. First, it is not recommended to accommodate e-learning content or treat learners differently according to their learning styles in blended programming courses. Students can achieve equally well irrespective of their individual preferences. This may be due to the malleability of learning styles as learners can easily adapt to different learning circumstances and teaching approaches. However, some changes in the way learning content is delivered in blended learning could be made to enhance perceived satisfaction of reflective learners. Second, in programming courses, the individual needs of both males and females can be addressed similarly without segregating them into two groups based on gender differences.

\section{Conclusion}

This research identified learning styles of engineering students in Iraq to show that their preferences in accordance with FSLSM are consistent with engineering students from other backgrounds. Then, the relationship among the deep level factor (learning styles), the surface level factor (gender), and learning experience in terms of performance and satisfaction was quantita- 
tively examined. The ILS was applied to infer learner styles, whereas three closed-ended questions and academic records were used to identify learning experience. From this analysis, many conclusions were drawn. First, the results of learning styles assumed that this trait did not significantly affect either academic achievement or perceived satisfaction except for the processing dimension, which demonstrated a significant association with the latter. Active learners were more satisfied in the blended learning mode than the reflective group. This may be because of the improvement of the social interaction between 'learner-learner' and 'learner-instructor' via the LMS, whereas reflective learners tend to study alone. Second, the study suggests that learning experience in programming courses is uncorrelated with gender. Participants achieved roughly similar mean scores irrespective of their gender differences. Finally, there is no significant relationship between learner achievement and perceived satisfaction.

The research has two main contributions. In keeping with prior literature, the study shares the existing critique regarding the implications of learning styles and gender on learning experience in blended programming modules. In addition, because of the scarcity of such studies in Arabic countries, it contributes to bridging the gap of current research, focusing on this population. In the future, participants from other disciplines and several universities will be integrated, in order for a general picture to be formed about the potential implications of the deep and surface level factors on learning experience in a blended learning mode. Interaction patterns of males and females in online settings will also be investigated in order to achieve a better understanding of the effect of gender on communication behaviour.

\section{Acknowledgment}

The authors are grateful to the Iraqi Ministry of Higher Education and Scientific Research for supporting this study. They would also like to thank Dr Lina P Varotsi for her constructive comments on the earlier version of the paper.

\section{References}

Adas, D., \& Shmais, W. A. (2011). Students' perceptions towards blended learning environment using the OCC. An-Najah University Journal for Research - Humanities, 25(6), 1681-1710.

Akbulut, Y., \& Cardak, C. S. (2012). Adaptive educational hypermedia accommodating learning styles: A content analysis of publications from 2000 to 2011. Computers \& Education, 58(2), 835-842. doi:10.1016/j.compedu.2011.10.008

Al-Azawei, A., \& Badii, A. (2014). State of the art of learning styles-based adaptive educational hypermedia systems (LS-BAEHSs). International Journal of Computer Science and Information Technology, 6(3), 1-19. doi:10.5121/ijcsit.2014.6301.

Al-Azawei, A., \& Lundqvist, K. (2014). The impacts of learning styles, learning patterns and demographic factors on learners' performance in a blended learning environment. Information Society (i-Society), International Conference. IEEE, pp.105-111.

Allert, J. (2004). Learning style and factors contributing to success in an introductory computer science course. Proceedings IEEE International Conference on Advanced Learning Technologies, 2004. doi:10.1109/ICALT.2004.1357442

Askar, P., Altun, A., \& Ilgaz, H. (2008). Learner satisfaction on blended learning. E-Leader Conference, Krakow, Poland.

Barrio-García, S., Arquero, J. L., \& Romero-Frías, E. (2015). Personal learning environments acceptance model: The role of need for cognition, e-learning satisfaction and students' perceptions. Educational Technology \& Society, 18(3), 129-141.

Bolliger, D. U., \& Wasilik, O. (2009). Factors influencing faculty satisfaction with online teaching and learning in higher education. Distance Education, 30(1), 103-116. doi:10.1080/01587910902845949 
Brown, E. (2007). The use of learning styles in adaptive hypermedia. Retrieved from http://etheses.nottingham.ac.uk/577/

Cagiltay, K., \& Bichelmeyer, B. (2000). Differences in learning styles in different cultures: A qualitative study. College Park, MD: ERIC Clearinghouse on Assessment and Evaluation.

Cha, H., Kim, Y., Park, S., \& Yoon, T. (2006). Learning styles diagnosis based on user interface behaviors for the customization of learning interfaces in an intelligent tutoring system. Intelligent Tutoring Systems. Springer Berlin Heidelberg, 513-524. Retrieved from http://link.springer.com/chapter/10.1007/11774303 51

Cheng, G., \& Chau, J. (2014). Exploring the relationships between learning styles, online participation, learning achievement and course satisfaction: An empirical study of a blended learning. British Journal of Educational Technology. doi:10.1111/bjet.12243

Chin, W. W. (1998). Issues and Opinion on structural equation modeling. MIS Quarterly, 22(1), 1. doi:Editorial

Chiu, C. M., Hsu, M. H., Sun, S. Y., Lin, T. C., \& Sun, P. C. (2005). Usability, quality, value and elearning continuance decisions. Computers and Education, 45, 399-416. doi:10.1016/j.compedu.2004.06.001

Coffield, F., Moseley, D., Hall, E., \& Ecclestone, K. (2004). Learning styles and pedagogy in post-16 learning: A systematic and critical review. London, UK: The Learning and Skills Research Centre

Cohen, L., Manion, L., \& Keith, M. (2007). Research methods in education (6th ed.). London, UK: Routledge.

Cook, D. A., \& Smith, A. J. (2006). Validity of index of learning styles scores: Multitrait-multimethod comparison with three cognitive/learning style instruments. Medical Education, 40, 900-907. doi:10.1111/j.1365-2929.2006.02542.x

Demirbas, O. O., \& Demirkan, H. (2007). Learning styles of design students and the relationship of academic performance and gender in design education. Learning and Instruction, 17(3), 345-359. doi:10.1016/j.learninstruc.2007.02.007

Dunn, R., Beaudry, J. S., \& Klavas, A. (2002). Survey of research on learning styles. California Journal of Science Education, 2(2), 75-99.

Fang, N., \& Zhao, X. (2013). A comparative study of learning style preferences between American and Chinese undergraduate engineering students. 2013 IEEE Frontiers in Education Conference (FIE), 1704-1705. doi:10.1109/FIE.2013.6685128

Felder, R. (1996). Matters of style. ASEE Prism, 6(4), 18-23.

Felder, R., \& Brent, R. (2005). Understanding student differences. Journal of Engineering Education, 94(1), 57-72. Retrieved from http://onlinelibrary.wiley.com/doi/10.1002/j.21689830.2005.tb00829.x/abstract

Felder, R. M., \& Soloman, B. A. (n.d.). Index of learning styles. Retrieved from http://www.engr.ncsu.edu/learningstyles/ilsweb.html

Felder, R., \& Silverman, L. (1988). Learning and teaching styles in engineering education. Engineering Education, 78(June), 674-681.

Felder, R., \& Spurlin, J. (2005). Applications, reliability and validity of the index of learning styles. International Journal of Engineering Education, 21(1).

Gable, G. G. (1994). Integrating case study and survey research methods: An example in information systems. European Journal of Information Systems, 3(2), 112-126.

Garrison, D. R., \& Kanuka, H. (2004). Blended learning: Uncovering its transformative potential in higher education. Internet and Higher Education, 7(2), 95-105. doi:10.1016/j.iheduc.2004.02.001 
The Effect of Learning Styles in Blended Programming Courses

Gefen, D., \& Straub, D. W. (1997). Gender differences in the perception and use of e-mail: An extension to the technology acceptance model. MIS Quarterly, 21, 389-400. doi:10.2307/249720

Gomes, A., \& Carmo, L. (2006). Mathematics and programming problem solving. Paper presented at 3rd E-Learning Conference - Computer Science Education, Coimbra, Portugal, September 7-8.

Gomes, A. J., \& Mendes, A. J. (2010). A study on student performance in first year CS courses. Proceedings of the Fifteenth Annual Conference on Innovation and Technology in Computer Science Education - ITiCSE '10, 113. doi:10.1145/1822090.1822123

Graf, S. (2007). Adaptivity in learning management systems focussing on learning styles. PhD dissertation Vienna: Vienna University of Technology.

Graf, S., Viola, S. R., \& Leo, T. (2007). In-depth analysis of the Felder-Silverman learning style dimensions. Journal of Research on Technology in Education, 40(1), 79-93. doi:10.1080/15391523.2007.10782498

Hair, J. F., Black, W. C., Babin, B. J., Anderson, R. E., \& Tatham, R. L. (2006). Multivariate data analysis (6th ed.). Upper Saddle River, NJ: Pearson Prentice Hall.

Henry, P. (2008). Learning style and learner satisfaction in a course delivery context. International Journal of Humanities and Social Sciences, 2(2), 47-50.

Honey, P., \& Mumford, A. (1992). The manual of learning styles. Berkshire, UK: Peter Honey Publications

Hong, K.-S. (2002). Relationships between students' and instructional variables with satisfaction and learning from a Web-based course. The Internet and Higher Education, 5(3), 267-281. doi:10.1016/S10967516(02)00105-7

Hosford, C. C., \& Siders, W. A. (2010). Felder-Soloman's index of learning styles: Internal consistency, temporal stability, and factor structure. Teaching and Learning in Medicine, 22(4), 298-303. doi:10.1080/10401334.2010.512832

Hsu, C. H. C. (1999). Learning styles of hospitality students: Nature or nurture? International Journal of Hospitality Management, 18(1), 17-30. doi:10.1016/S0278-4319(98)00045-0

Kaghed, N., \& Dezaye, A. (2009). Quality assurance strategies of higher education in Iraq and Kurdistan: A case study. Quality in Higher Education, 15(1), 71-77. doi:10.1080/13538320902731286

Kolb, D. (1984). Experiential learning: Experience as the source of learning and development. Retrieved from http://academic.regis.edu/ed205/Kolb.pdf

Kuri, N. P., \& Truzzi, S. (2002). Learning styles of freshmen engineering students. Proceedings ICEE Annual Conference on Engineering Education, UNESCO International Centre for Engineering Education, Arlington, VA.

Lahtinen, E., Ala-Mutka, K., \& Järvinen, H.-M. (2005). A study of the difficulties of novice programmers. ACM SIGCSE Bulletin, 37(3), 14. doi:10.1145/1151954.1067453

Lau, W. W. F., \& Yuen, A. H. K. (2009). Exploring the effects of gender and learning styles on computer programming performance: implications for programming pedagogy. British Journal of Educational Technology, 40(4), 696-712. doi:10.1111/j.1467-8535.2008.00847.x

Lee, C. K., \& Sidhu, M. S. (2015). Engineering students learning preferences in UNITEN: Comparative study and patterns of learning styles. Educational Technology \& Society, 18(3), 266-281.

Litzinger, T. A., Lee, S. H., Wise, J. C., \& Felder, R. M. (2005). A study of the reliability and validity of the Felder-Soloman index of learning styles. Engineering Education, 113, 77.

Litzinger, T. A., Lee, S. H., Wise, J. C., \& Felder, R. M. (2007). A psychometric study of the index of learning styles@ ${ }^{0}$. Journal of Engineering Education, 96(4), 309-319. doi:10.1002/j.21689830.2007.tb00941.x

Litzinger, T., Lee, S., Wise, J., \& Felder, R. M. (2005). A study of the reliability and validity of the FelderSoloman index of learning styles. Education, 113(77) 
Lowry, P. B., \& Gaskin, J. (2014). Partial least squares (PLS) structural equation modeling (SEM) for building and testing behavioral causal theory: When to choose it and how to use it. IEEE Transactions on Professional Communication, 57(2), 123-146. doi:10.1109/TPC.2014.2312452

Mahmud, S. F. (2013). The higher education in Iraq: Challenges and recommendations. Journal of Advanced Social Research, 3(9), 255-264.

Mayer, R. E. (2011). Does styles research have useful implications for educational practice? Learning and Individual Differences, 21(3), 319-320. doi:10.1016/j.lindif.2010.11.016

Mcdowell, C., Werner, L., Bullock, H. E., \& Fernald, J. (2003). The impact of pair programming on student performance, perception and persistence. Proceedings of the 25th International Conference on Software Engineering (pp. 602-607). doi:10.1109/ICSE.2003.1201243

Naaj, M., Nachouki, M., \& Ankit, A. (2012). Evaluating student satisfaction with blended learning in a gender-segregated environment. Journal of Information Technology Education: Research, 11(1), 185200. Retrieved from http://www.jite.org/documents/Vol11/JITEv11p185-200AbouNaaj0979.pdf

Özyurt, Ö., \& Özyurt, H. (2015). Learning style based individualized adaptive e-learning environments: Content analysis of the articles published from 2005 to 2014. Computers in Human Behavior, 52, 349358 .

Oxford, R. L., \& Anderson, N. J. (1995). A crosscultural view of learning styles. Language Teaching, 28(04), 201. doi:10.1017/S0261444800000446

Pashler, H., McDaniel, M., Rohrer, D., \& Bjork, R. (2009). Learning styles, concept and evidence. Psychological Science in the Public Interest, 9(3), 105-119.

Pioro, B. T. (2004). Performance in an introductory computer programming course as a predictor of future success for engineering and computer science majors authors. International Conference on Engineering Education, Gainesville, Florida.

Popescu, E. (2010). Adaptation provisioning with respect to learning styles in a web-based educational system: an experimental study. Journal of Computer Assisted Learning, 26(4), 243-257. doi:10.1111/j.1365-2729.2010.00364.x

Prajapati, B., Dunne, M., Bartlett, H., \& Cubbidge, R. (2011). The influence of learning styles, enrolment status and gender on academic performance of optometry undergraduates. Ophthalmic and Physiological Optics, 31(1), 69-78. doi:10.1111/j.1475-1313.2010.00798.x

Shaw, R. S. (2012). A study of the relationships among learning styles, participation types, and performance in programming language learning supported by online forums. Computers and Education, 58(1), 111-120. doi:10.1016/j.compedu.2011.08.013

Shin, W. S., \& Kang, M. (2015). The use of a mobile learning management system at an online university and its effect on learning satisfaction and achievement. International Review of Research in Open and Distributed Learning, 16(3), 110-130.

Tarhini, A., Hassouna, M., \& Abbasi, M. S. (2015). Towards the acceptance of RSS to support learning: An empirical study to validate the Technology Acceptance Model in Lebanon. Electronic Journal of ELearning, 13(1), 30-41.

Thomas, L., Ratcliffe, M., Woodbury, J., \& Jarman, E. (2002). Learning styles and performance in the introductory programming sequence. Proceedings of the 33rd SIGCSE Technical Symposium on Computer Science Education - SIGCSE '02, 33. doi:10.1145/563351.563352

Van Zwanenberg, N., Wilkinson, L. J., \& Anderson, A. (2000). Felder and Silverman's index of learning styles and Honey and Mumford's learning styles questionnaire: How do they compare and do they predict academic performance? Educational Psychology, 20(3), 365-380. doi:10.1080/713663743

Vanderheyden, K., \& De Baets, S. (2015). Does cognitive style diversity affect performance in dyadic student teams? Learning and Individual Differences, 38, 143-150. doi:10.1016/j.lindif.2015.01.006 
Willingham, D. T., Hughes, E. M., \& Dobolyi, D. G. (2015). The scientific status of learning styles theories. Teaching of Psychology, 42(3), 266-271. doi:10.1177/0098628315589505

Wong, J. K. K. (2004). Are the learning styles of Asian international students culturally or contextually based? International Education Journal, 4(4), 154-166.

Wu, J.H., Tennyson, R. D., \& Hsia, T.L. (2010). A study of student satisfaction in a blended e-learning system environment. Computers \& Education, 55(1), 155-164. doi:10.1016/j.compedu.2009.12.012

Yukselturk, E., \& Bulut, S. (2009). Gender differences in self-regulated online learning environment gender differences in self-regulated learning. Educational Technology \& Society, 12(3), 12-22.

Zywno, M. (2003a). A contribution to validation of score meaning for Felder-Soloman's index of learning styles. In Proceedings of the 2003 American Society for Engineering Education Annual Conference \& Exposition, 119, 1-5.

Zywno, M. S. (2003b). The effect of individual differences on learning outcomes through hypermediabased instruction. PhD thesis. Glasgow, UK: Glasgow Caledonian University.

\section{Biographies}

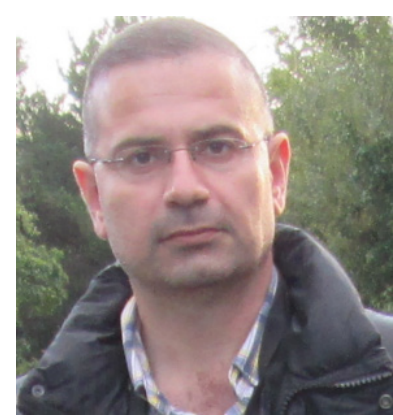

Ahmed Al-Azawei is a $\mathrm{PhD}$ student at the University of Reading. He is also a lecturer at the College of Information Technology, the University of Babylon, and his area of research focuses on learner differences, e-learning adoption and application, inclusive learning theories, and adaptive educational hypermedia systems. His research aims to enhance the implementation of learning technologies in higher education in developing countries in order to respond to learner differences. Ahmed has published many papers in several international journals and conferences

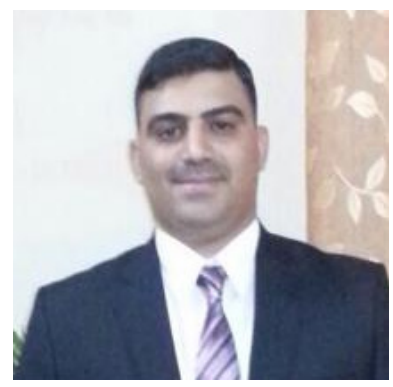

Ali Al-Bermani received his MSc in computer science. Currently, he is a lecturer in the College of Information Technology at the University of Babylon. His area of research focuses on pattern recognition, interaction design, and web programming. In his classes, Ali presents a wide range of tools and software to students, assisting them to master dynamic web design.

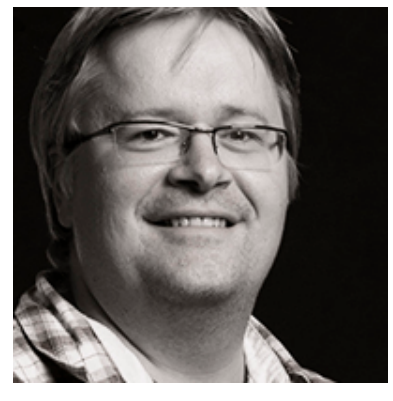

Dr Karsten Lundqvist is a lecturer in the School of Systems Engineering at the University of Reading, and his area of research focuses on e-learning, its application and the usage of AI techniques within teaching and learning. Examples of his work include game-based learning, automated tutoring tools, social networking in connectivist learning in higher education, and natural language tools in learning situations. He is also known, as an e-learning practitioner, through the popular MOOC "Begin Programming: Build your first mobile game", which runs on the FutureLearn platform. 